\title{
A Study on Integrity and Education of College Students
}

\author{
$\mathrm{Na} \mathrm{Li}^{1, \mathrm{a}}$ and Chao Wang ${ }^{\mathrm{b},}$ * \\ 1,2Xincheng Street 2888, Jilin Agricultural University, Changchun, Jilin Province 130118, PR China \\ a350202380@qq.com,,29251275@qq.com \\ *The Corresponding author
}

Keywords: College students; Integrity; Way research

\begin{abstract}
Sincerity also is the integrity. The so-called integrity is the conduct of the country, it is self-cultivation of the Road. The core values of socialism pointed out at the individual level that "patriotism, professionalism, integrity and friendliness" have established the benchmarks of ideological and moral behavior. Among them, Integrity education should become the top priority of contemporary college students' ideological and moral education. This paper expounds the seriousness of the lack of Integrity in college students, analyzes and thinks about the reasons, and gives the countermeasures and suggestions to strengthen the Integrity education of college students.
\end{abstract}

\section{Introduction}

In recent years, with the socio-economic growth, as well as the social transformation of the adverse social atmosphere of the impact of the crisis quickly spread to people's lives in various fields, a serious lack of trust between people, this phenomenon in the middle of contemporary college students is particularly prominent. In this paper, the "integrity education of contemporary Chinese college students", from the analysis of the status situation of college students integrity, resulting in the reasons for the lack of integrity and enhance the integrity of education initiatives in three aspects of the depth of analysis.

\section{An Analysis of the Status Situation of Integrity of Contemporary College Students}

Formal Academic Integrity. In the strong advocacy of academic integrity today, there are still many people hold high the banner of integrity for academic fraud. We can see that college students plagiarism, plagiarism, data fraud and other academic scandals are exposed, the most rigorous, the most sacred science hall so cast a shadow, academic corruption makes the scientific development and social progress has been seriously hampered, and the academic atmosphere and moral environment has a great relationship [1].The reason why advocacy academic integrity, is to purify the academic team, washing academic dirt. However, the number of college students is increasing, academic fraud also will become increasingly serious. Learning is not refined, difficult to learn, make good enough, muddle through etc. these phenomena make academic integrity in name only. Many undergraduates to write graduation thesis holding perfunctory attitude, not to read the reference literature, but directly to the contents of the literature, the whole "reference"; change the subject, another author on the temporary concocted papers everywhere. We advocate the academic integrity, in the plagiarism of the prevalence of contemporary university campus, has been beyond recognition. Not only that, college educators also exist plagiarism fraud phenomenon, Xi'an Jiaotong University, Professor Li Liansheng and other scientific and technological achievements fraud, the former president of Tsinghua University School of Medicine Liu Hui forged personal resume events, are academic fraud there is a strong evidence The This kind of "upside down" academic fraud, resulting in a very bad influence, greatly hindered the pace of college students integrity education.

Rely on Loan integrity. In order to solve the pressure of school students with financial difficulties, the state has set up an unsecured national student loan. Not yet perfect personal credit system, making the repayment of loans based on the quality of integrity and integrity of college 
students on the basis of quality, it also caused the lack of college students credit status situation [2].The national student loan policy is an early consumption of human resources for college students. The state helps families to solve the problem of difficulty in school, alleviate their family burden, and because of the poor repayment caused by the phenomenon of non-repayment Is unexpected. This phenomenon of arrears does not only affect the national student loan this special funds turnover, but also to the lower grades of student loans caused difficulties. As a high-quality talent, college students should be aware that both the loan, you need to repay, can not hold the "heaven off the pie" chances, that this is the national welfare policy, On the other hand, the weak repayment of college students also bring great trouble to the bank. In the process of national student loans, commercial banks not only do not get the corresponding substantive encouragement, but must bear the national student loan amount is small, involves a wide range of work and other characteristics brought about by the high transaction costs, management costs, as well as the high recovery costs and default losses [3].

Words not Match Deeds of Employment Integrity. In the process of employment including a series of activities such as resume production, interview and signing of employment agreement, there is a particularly obvious disIntegrity. First of all, false grades, qualifications, award certificates often appear in the resume. Resume is to sell their own leaflets, real self-awareness, self-evaluation is conducive to self-improvement in the future work. However, college students in the resume in the fictional school job and performance is very common. In addition, in the process of employment, even if the contract has been signed in the face of difficult employment environment and brutal employment competition, some college students lack the sense of integrity, contract concept is weak, with the employer signed a tripartite agreement, do a set to find the relative Better employment units do not report after, and some even at the breach of contract. Labor contract is used to bind the contract between the employer and the graduates, signed a labor contract should have a good sense of integrity and professional quality, repeated breach of time not only to the graduates themselves wearing a bad hat, the employer is also Which bear the serious consequences, seriously affected their work plan to complete the work. At the same time, their own school in the community's overall credibility will decline. In order to find a good place for today's severe employment situation and employment pressure, it is understandable that college students should make appropriate modifications to their evaluation in the process of job search. However, once the facts are exaggerated, the consequences can not be avoided.

\section{The Causes of the Lack of Integrity in College Students}

The Impact of the Social Environment. With fierce competition in the market economy, people are increasingly pursuing the maximization of personal interests, economic interests to bring people is the lack of trust. Lack of integrity, lack of integrity of the phenomenon abound, for example, around the school walls often see false advertising, the market is not uncommon fake and shoddy goods, a lot of corporate tax evasion and in the production and processing cut corners, etc., all levels of society are subject to its strong Impact. In the values, outlook on life, world outlook, the formation of critical period of college students, the most vulnerable to its adverse effects [4]. Water can be carried by the boat can also be over the boat, the integrity of the social environment to create excellent talent, bad social atmosphere can also make people moral quality decline. There are loopholes in the social system and the law. Law is the guarantee of morality, morality is the supervision of the law. A strong legal system can more effectively constrain people's bad faith behavior. The face of the loopholes in the law, a large part of people feel luck, drilling system loopholes, playing the edge of the ball etc., so that everywhere and contrary to the integrity of people who are difficult to be punished, but also contributed to the style of disIntegrity, contributed to disIntegrity the spread.

The Influence of Moral Education Disadvantages in Colleges. Have to admit that integrity education has always been the focus of teaching in colleges and universities. However, there is also a great drawback in the integrity education of colleges and universities, which also directly affects the improvement of moral quality of college students. For a long time, a certain degree of 
abstraction, hollowing and formalization is the abuse of moral education in our country, the traditional sense of the education system is based on exam-oriented education, and therefore relatively weakened the students of moral education, morality education is only in the form of preaching and not really implemented. The reason why college students lack of integrity, mainly because of the existence of knowledge, they think that as long as the awareness increased, the behavior must follow the norms. However, Integrity is not just a simple moral awareness, but also a need to do the behavior. We emphasize that students want to know the unity of the line, but often know and not, so formal education seriously led to the integrity of knowledge and the separation of knowledge. At the same time, students will have such an idea of psychological, honest education and moral education are just talk about it, listen to see on the past, and their own little relationship. This kind of "nothing matter, high hanging" attitude once formed, making the integrity of education in colleges and universities is even more difficult.

The Lack of Personal Moral Qualities. Weak moral consciousness is the fundamental lack of integrity of college students. The impact of the external environment, after all, only objective factors, only from the heart of their own understanding of the importance of integrity, the real from the bones to hold the final moral bottom line, so that integrity in the hearts of the tree to the integrity of the wind, integrity of the matter. Although the contemporary college students are active and open, the individual consciousness is enhanced, but their lack of social experience, life experience is relatively simple, often their own concerns about the limitations and limitations of social phenomena in the context of market economy development, Part of the lack of rational thinking and analysis of the ability to judge, vulnerable to the interests of the community driven, which formed a self-centered distorted psychology, resulting in a serious money worship. In their understanding, only the greatest self-interest, as long as it is beneficial to their own things, to unscrupulous to do, even if it is contrary to the integrity of anyway. In the face of the so-called "iron buddy" friendship, high compensation for adult education for a test, a lot of college students will still take the risk to help them, not knowing that this is both harm others, but also harm themselves. In the college students, the mutual influence between people, so that the spread of bad faith, the formation of a huge butterfly effect, and ultimately become the integrity of education in colleges and universities is not an important reason.

\section{A Study on the Ways to Strengthen College Students' Integrity Education}

The Core Values of Socialism -- the Ideas of Integrity Education. The 18th National Congress of the Communist Party of China proposed to cultivate and practice the socialist core values. "Patriotism, dedication, integrity, friendliness" as a citizen of the individual level of value criteria, integrity education is one of the most important part. Contemporary college students are the practitioners of socialist core values, the pioneers who realize the great revival of Chinese dreams, and guide the integrity education of college students with the socialist core values so as to truly enhance the effectiveness of Integrityeducation. The reason why the existence of modern college students lack of integrity, a large part of the reasons attributed to personal values. The socialist core values have put forward more stringent standards at the national level, at the social level and at the individual level. This criterion will guide the integrity education of college students on track. Colleges and universities should actively carry out the theme of honest education under the guidance of the socialist core values, promote the integrity of the typical, continue to guide students to join the integrity of the army, to help students in the mind to establish a correct world outlook, outlook on life and values. Only to allow students to truly realize that people should not be a pure relationship between the interests in order to let them out of the wrong values in order to set up a bridge between people in good faith communication in order to make them realize that integrity is right The necessary conditions for things. Only from the ideological, values have been changed, treachery, the lack of integrity in the form of the phenomenon can be gradually disappear.

The Unity of Knowledge and Practice in Higher Education - The Code of Conduct for IntegrityEducation. The IntegrityEducation in Colleges and Universities Must Establish a Perfect Educational System. The integrity of the students education, not a few posters, a few banners will 
be able to achieve the purpose of education, but to penetrate the students to learn all aspects of life. We need to establish the integrity of the file, the daily behavior of students to monitor each other, the establishment of integrity of the student organization department, from the teacher in the academic do not copy, do not fake etc..

First, establish a complete integrity file. The implementation of theoretical education in the dynamic process, we must grasp the integrity of the students in a timely manner to the students as a carrier of personnel files, relying on college students integrity management record mechanism, the integrity of the integrity of the file size of students planning, at the same time, archiving management open, record the updated, the formation of a complete scientific integrity of the file management mechanism [5].

Second, the establishment of self-discipline and other-discipline evaluation system. First, we should establish a self-integrity evaluation system, college students from time to time on their own performance to do good faith evaluation, at the same time for the bad side to do to improve. Second, for self-binding students, the establishment of other law evaluation system, the group as a unit of his law, through the surrounding students to their own integrity evaluation to restrain themselves; the same time, college students ideological and political counselors, curriculum teachers should To do the example of integrity, academic do not copy, do not fake, to their own integrity, their own strong personality to influence students, students, education students, so that students and teachers to monitor each other in order to ensure integrity education Transparency; Finally, in the perfect self-discipline and other law evaluation system based on the establishment of reward and punishment system, through praise and recognition, to encourage students to self-confidence into self-demand, we all fight to become a typical virtuous circle, these will be better To improve the enthusiasm of college students practice integrity.

\section{Acknowledgements}

Jilin Provincial Department of Education "thirteen five" social science research project: Jilin Educational, Scientific and Cultural Organization, NO.[2017] JJKH20170337JY

\section{References}

[1] Xie Guo, Wu Minzhi, Cai Peixin, Cai Weiyu, Chen Jingyun, Wang Yuehui. The investigation and countermeasures of Independent college science and engineering students plagiarism [J] .Guangzhou Chemical Industry, 2012 (16)

[2] Liu Dongsheng.Study on the Construction of IntegritySystem for National Student Loans in Colleges and Universities [D]. Southwest University, 2006 (6)

[3] Yu Haiyang. The status situation and countermeasures analysis on the national student loan work [J]. Ideological and political education research, 2007 (4)

[4] Cai Xiulei, Zhou Shun. Investigation on Integrityand Credit of College Students and Research on IntegrityEducation. Journal of Shandong Youth Management Cadre College, 2010 (9)

[5] Tu Xianjing. Study on the integrity education of college students in the new era [D]. Southwestern University, 2009 